\title{
Assessment of skid resistance using DFTester and CTMeter
}

\author{
Marta Wasilewska, Wladyslaw Gardziejczyk, Pawel Gierasimiuk \\ Bialystok University of Technology, Faculty of Civil and Environment Engineering \\ Wiejska 45E, Bialystok 15-351, Poland
}

\begin{abstract}
Skid resistance is related to pavement surface texture which include the wavelength ranges described by microtexture and macrotexture. Microtexture, with wavelengths less than $0.5 \mathrm{~mm}$, depends on the surfaces of coarse aggregate particles, fine aggregate in asphalt mixture. It is associated with good skid resistance on wet roads. Macrotexture is depend on asphalt mixture properties (shape, size, and gradation of aggregate) and has an effect on skid resistance especially at high vehicle speed. In this paper skid resistance of different pavement surface textures based on IFI (International Friction Index) are compared. IFI (F60, Sp) was calculated using the MPD from the CTMeter (Circular Track Meter) measurement and the DF20 at a slip speed of $20 \mathrm{kph}$ from the DFTester (Dynamic Friction Tester) measurement. Asphalt concrete and SMA pavements were measured in this study. In addition, the coefficient of friction $F(S)$ was calculated at various slip speeds $\mathrm{S}$. The influence of asphalt mixture composite, coarse aggregates polishing and site location (junction, straight and curve segments) were analyzed. As the result of the analysis it was found that at low speed pavements made of asphalt concrete had higher coefficient of friction than SMA pavements, while at high speeds SMA pavements had higher coefficient of friction than asphalt concrete pavements. Coefficient of friction have lower values on curves and junctions than on straight road segments on the same type of pavement. This may be valuable information for proper maintenance of existing pavements and on the stage of designing.
\end{abstract}

Keywords: skid resistance; pavement surface texture; wearing course; coefficient of friction.

\begin{tabular}{|ll}
\hline Nomenclature \\
AC & asphalt concrete \\
DF20 & coefficient of friction at slip speed 20kph \\
IFI & International Friction Index \\
F60 & Friction Number \\
F(S) & coefficient of friction at any slip speed S \\
MPD & Mean Profile Depth (mm) \\
S & slip speed $(\mathrm{kph})$ \\
Sp & Speed Number $(\mathrm{kph})$ \\
SMA & stone mastic asphalt \\
PSV & Polished Stone Value \\
V & Coefficient of variation $(\%)$ \\
\hline
\end{tabular}

\section{Introduction}

Skid resistance plays an important role on the safety on roads. On wet surface the skid resistance significantly decreases and the number of accidents increases strongly. It has been proven that maintaining on the required level of skid resistance considering characteristic of wearing course, traffic load and sites location influence reduction of road accidents (to 25\%) [1], [2]. Particular attention is paid on establishing higher requirements for areas where vehicles are especially exposed to slipping, where there is a risk of sudden braking (pedestrian crossing, junction, horizontal curve $<250 \mathrm{~m}$ radius, longitudinal gradient $>6 \%)[3]$. 
Skid resistance is related to pavement surface texture. Pavement surface texture is specified in the three-level scale, each defined by the wavelength $(\lambda)$ and peak - to peak amplitude (A) of its components. According to the division, which was established in 1987 by the Permanent International Association of Road Congresses (PIARC) there are: megatexture $(\lambda=50$ to $500 \mathrm{~mm} ; A=0.1$ to $50 \mathrm{~mm})$, macrotexture $(\lambda=0.5$ to $50 \mathrm{~mm} ; A=0.1$ to $20 \mathrm{~mm})$, microtexture $(\lambda<0.5 \mathrm{~mm} ; A=1$ to 500 $\mu \mathrm{m})$ [1]. Especially macrotexture and microtexture influence skid resistance. Macrotexture depends on asphalt mixture properties (shape, size and gradation of aggregate) and has an effect on skid resistance especially at high vehicle speed. Macrotexture can be characterized by the MTD (Mean Texture Depth) parameter obtained by volumetric method or the MPD (Mean Profile Depth) parameter obtained by method profilometry. Currently there are many laser devices for evaluation of macrotexture in use. One of them is CTMeter (Circular Track Meter).

Microtexture depends on polishing resistance of coarse aggregate and content of fine aggregate in asphalt mixture. In actual traffic conditions the phenomenon of polishing of the protruding aggregate grains is caused by traffic. Due to the fact that microtexture existis on a microscopic scale, it is very difficult to assess it. PSV (Polished Stone Value) is used indirect method to assess microtexture of coarse aggregates. However it is difficult to explain microtexture only on the basis of PSV. Microtexture can be estimated using low speed friction measurement devices such as the BPT (British Portable Tester) or the DF Tester (Dynamic Friction Tester).

There are many different devices for assessing of skid resistance. Devices for measuring coefficients of friction are divided into four modes: locked wheel, side - force, fixed slip and variable slip In Poland skid resistance is assessed on the basis of coefficient of friction measured by SRT-3 device with locked wheel. The criteria for evaluation do not include site location of tested wearing course. SRT-3 can only be used on straight segments, no curves, junctions, roundabouts or crossings. Locked wheel measurement due the fact of locked tire is general not conclusive to reflect changes of both mictotexture and macrotexture. In most European countries the fixe slip or side-force devices are used, which measure the coefficient of friction during the slip in the range $13-34 \%$. Such methods are meant to test surfaces under emergency braking conditions for vehicle with anti-lock brakes [1].

The PIARC proposed in 1995 an IFI (International Friction Index) for use in surveys of pavement friction. IFI is based on a mathematical model (called the PIARC Friction Model) describing the friction coefficient as a function of slip speed and macrotexture. The IFI uses two parameters: F60 (the common friction value at a slip speed of $60 \mathrm{kph}$ ) and Sp (the speed constant, which is based on a texture measurement). According to the standard ASTM E1960 - 07 (2011) IFI can be calculated using the MPD from the CTM measurement and the DF20 at a slip speed of $20 \mathrm{kph}$ from the DFT measurement [4], [5].

Study on development of criteria for assessing skid resistance is conducted at Bialystok University of Technology. In this paper the possibility of using CTM and DFT for assessment of wearing course made from SMA (stone mastic asphalt) and $\mathrm{AC}$ (asphalt concrete) is presented. Tests were made on surfaces of main and secondary roads, deceleration lanes, curves and junction entries.

\section{Research program}

\subsection{Selection of test section}

The selection of test sections were depended on wearing course characteristic and site conditions. In this study seven test sections were considered. Wearing courses of AC and SMA were chosen. These types of wearing course are most popular in Poland. The test mixtures had the same maximum aggregate size and similar PSV. Table 1 shows description of the test sections and Tables 2 and 3 - characteristic of asphalt mixture.

\begin{tabular}{lllll} 
Table 1. Sites & \multicolumn{1}{l}{} \\
\hline Test section No. & Mixture No. & Definition of test section & Section length [m] & Date laid \\
\hline 1 & B & Maid road & 1000 & 2012 \\
2 & A & Maid road & 1000 & 2012 \\
3 & A & Deceleration lane & 200 & 2012 \\
4 & C & Secondary road & 1000 & 2012 \\
5 & C & Curve, R $=40 \mathrm{~m}$ & 100 & 2012 \\
6 & C & Curve, R $=30 \mathrm{~m}$ & 100 & 2012 \\
7 & C & Junction area & 3 entry & 2012 \\
\hline
\end{tabular}

Table 2. Description of asphalt mixes and aggregates

\begin{tabular}{llllllll}
\hline Mixture No. & Asphalt mixture & $\begin{array}{l}\text { Maximum } \\
{[\mathrm{mm}]}\end{array}$ & size & Asphalt type & $\begin{array}{l}\text { Asphalt } \\
\text { content (\%) }\end{array}$ & $\begin{array}{l}\text { Air } \\
(\%)\end{array}$ & $\begin{array}{c}\text { voids, } \\
\text { Aggregates } \\
\text { type }\end{array}$ \\
\hline A & SMA & 11 & PMB 45/80-65 & 6.4 & 3.2 & Melaphir & 52 \\
B & SMA & 11 & PMB 45/80-65 & 6.4 & 3.1 & Granodioryt & 52 \\
C & AC & 11 & PMB 45/80-55 & 5.4 & 2.1 & Glacial & 53 \\
\hline
\end{tabular}


Table 3. Aggregate particle-size distribution

\begin{tabular}{lllllllll}
\hline Mixture & \multicolumn{1}{l}{ Particle size distribution } & & & & & \\
\cline { 2 - 9 } & Sieve $(\mathrm{mm})$ & 0.063 & 0.125 & 2 & 4 & 5.6 & 8 & 11.2 \\
\hline A & Passing fraction & 10.3 & 13 & 25 & 33 & 41 & 62 & 96 \\
B & Passing fraction & 10.2 & 12 & 27 & 30 & 40 & 62 & 96 \\
C & Passing fraction & 6.5 & 13 & 45 & 30 & 40 & 62 & 96 \\
\hline
\end{tabular}

\subsection{Devices}

The DFTester and the CTMeter were used in this investigations (Figs 1 and 2). The DFTester is a portable device that allows measuring coefficient of friction. The DFT consists of a horizontal spinning disk fitted with three spring loaded rubber sliders that contact the surface. The disk rotates at tangential velocities up to $80 \mathrm{kph}$. Water flows over the surface being tested. The rotating disk is then dropped onto the wet surface and the coefficient of friction is continuously measured as the disk slows. Measuring is available in the range of start speed $20-80 \mathrm{kph}$. At the start speed of $80 \mathrm{kph}$ the values of coefficient of friction DF20, DF40, DF60 are calculated, at the speed of 60kph - DF40 and DF20, at the start speed 40 kph only DF20. In this study, tests were carried out at start speed $80 \mathrm{kph}$.
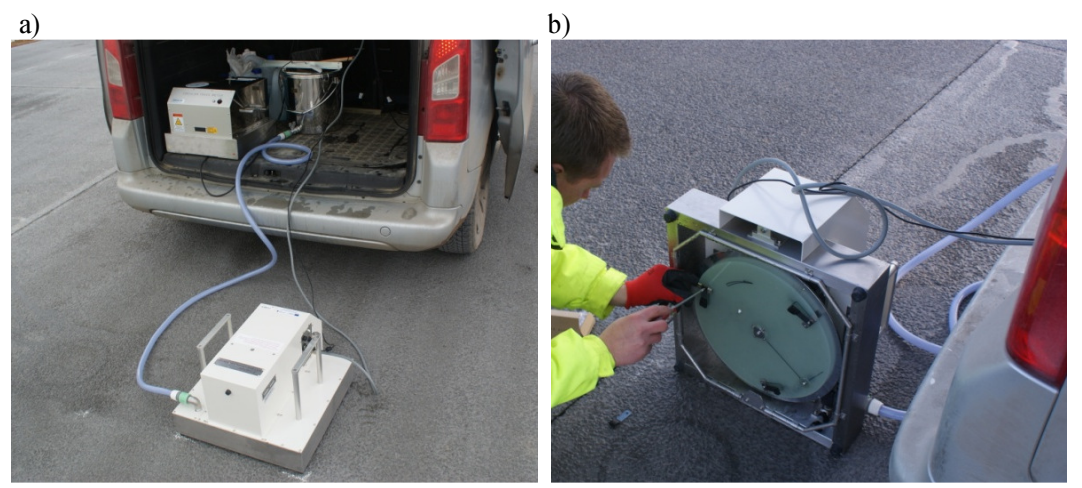

Fig. 1. DFtester device a) during the measurement surface b) view of disk with rubber sliders

The CTMeter is a road surface macrotexture profiler that uses a charge coupled device (CCD) laser-displacement sensor to measure the vertical profile of a pavement surface. When the measurement is started the CCD Laser Displacement Sensor rotates on a circumference with a $142 \mathrm{~mm}$ radius and measures the texture with a sampling interval of approximately $0.9 \mathrm{~mm}$. The macrotexture was measured in the exact same physical areas as the DFT measurements were taken. The CTMeter software calculates and reports the Mean Profile Depth (MPD) and Root Mean Square (RMS) statistics that characterize profile macrotexture.
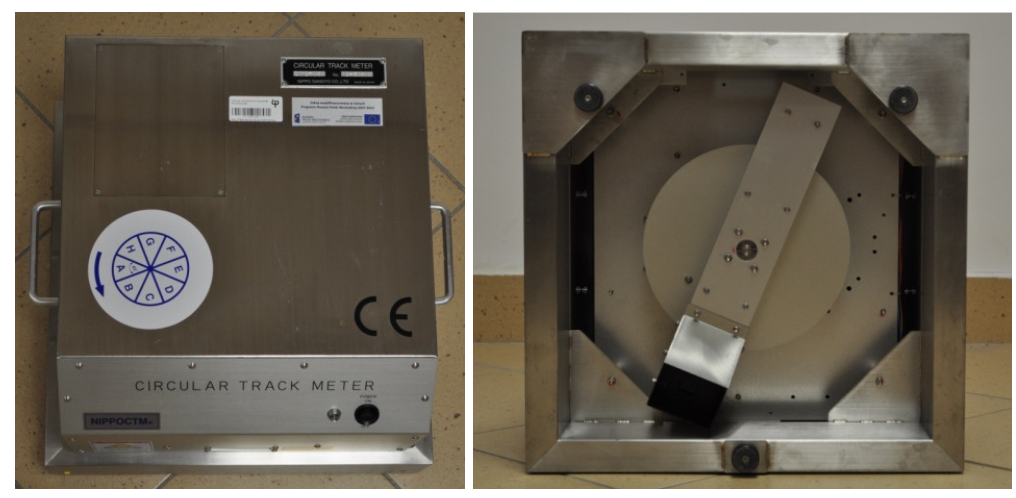

Fig. 2. CTMeter device

\subsection{Test procedure}

The measurements with DFTester i CTMeter were conducted on both left and right wheel paths on:

- main and secondary roads on the section length 1000 m every 100 m;

- deceleration lane on the section length $200 \mathrm{~m}$ every $50 \mathrm{~m}$ (Fig. 3a);

- curves on the section length $100 \mathrm{~m}$ every $20 \mathrm{~m}$. 
Fig. $3 \mathrm{~b}$ shows testing sites on the junction entries. Measurements require lane closure. Testing was conducted on the same day and at stable temperatures $\left(22-25^{\circ} \mathrm{C}\right)$.
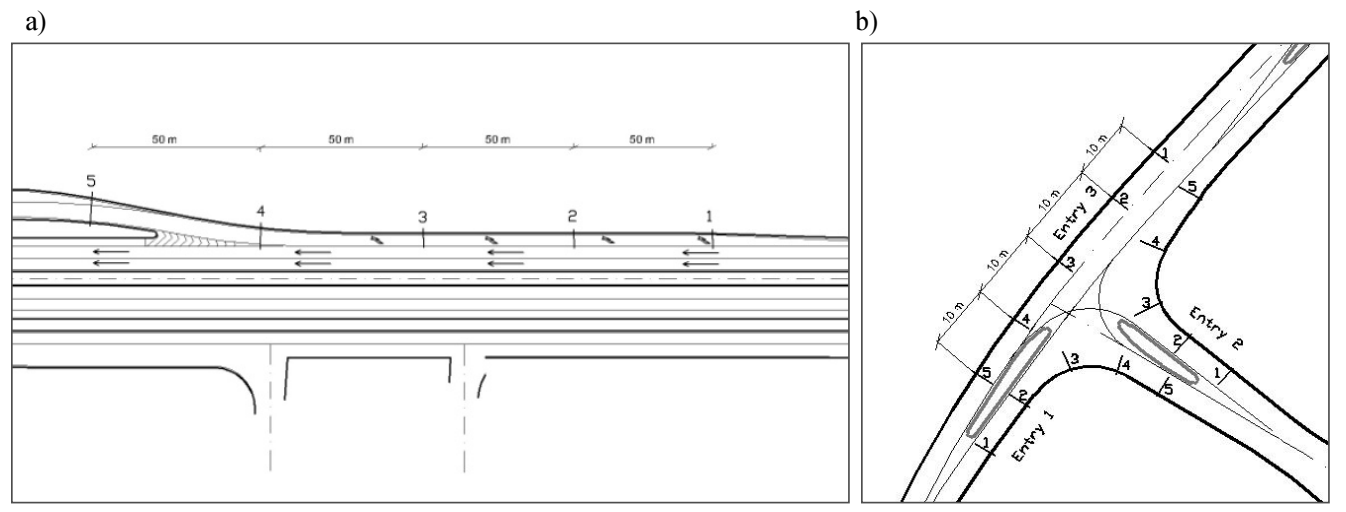

Fig. 3. Measuring points on the test sections a) deceleration lane, b) junction entries

\section{Results and analysis}

Values of DF20, MPD including average values, STD (standard deviations) and V (coefficient of variation) are presented in

Tabels 4-6.

Table 4. DF20, MPD and statistical values from 1,2 and 4 test sections

\begin{tabular}{|c|c|c|c|c|c|c|c|c|c|c|c|c|}
\hline \multirow{3}{*}{$\begin{array}{l}\text { Measuring } \\
\text { point }\end{array}$} & \multicolumn{4}{|l|}{1} & \multicolumn{4}{|l|}{2} & \multicolumn{4}{|l|}{4} \\
\hline & Left & & Right & & Left & & Right & & Left & & Right & \\
\hline & DF20 & MPD & DF20 & MPD & DF20 & MPD & DF20 & MPD & DF20 & MPD & DF20 & MPD \\
\hline 1 & 0.50 & 0.85 & 0.50 & 0.96 & 0.52 & 1.37 & 0.51 & 1.08 & 0.66 & 0.36 & 0.64 & 0.27 \\
\hline 2 & 0.46 & 0.85 & 0.51 & 0.88 & 0.51 & 1.16 & 0.44 & 0.94 & 0.60 & 0.39 & 0.62 & 0.35 \\
\hline 3 & 0.51 & 0.86 & 0.52 & 0.80 & 0.52 & 0.98 & 0.50 & 0.89 & 0.63 & 0.34 & 0.60 & 0.31 \\
\hline 4 & 0.49 & 1.04 & 0.51 & 1.13 & 0.53 & 1.03 & 0.52 & 0.93 & 0.62 & 0.47 & 0.61 & 0.28 \\
\hline 5 & 0.51 & 0.78 & 0.50 & 0.81 & 0.48 & 1.37 & 0.53 & 0.96 & 0.66 & 0.41 & 0.62 & 0.27 \\
\hline 6 & 0.53 & 0.83 & 0.51 & 0.77 & 0.53 & 1.15 & 0.50 & 0.98 & 0.61 & 0.45 & 0.65 & 0.23 \\
\hline 7 & 0.51 & 0.81 & 0.50 & 0.76 & 0.53 & 1.26 & 0.52 & 0.91 & 0.69 & 0.37 & 0.59 & 0.31 \\
\hline 8 & 0.52 & 0.73 & 0.51 & 0.63 & 0.54 & 1.12 & 0.48 & 1.12 & 0.65 & 0.36 & 0.62 & 0.32 \\
\hline 9 & 0.44 & 0.97 & 0.52 & 1.08 & 0.55 & 1.31 & 0.56 & 1.30 & 0.63 & 0.39 & 0.64 & 0.34 \\
\hline 10 & 0.50 & 1.01 & 0.50 & 0.88 & 0.53 & 1.13 & 0.52 & 1.07 & 0.65 & 0.41 & 0.63 & 0.36 \\
\hline Average & 0.50 & 0.87 & 0.51 & 0.87 & 0.52 & 1.19 & 0.51 & 1.03 & 0.64 & 0.40 & 0.62 & 0.30 \\
\hline STD & 0.03 & 0.10 & 0.01 & 0.14 & 0.02 & 0.13 & 0.03 & 0.14 & 0.03 & 0.04 & 0.02 & 0.04 \\
\hline V (\%) & 5.25 & 11.00 & 1.47 & 16.59 & 3.44 & 10.80 & 5.26 & 13.86 & 4.01 & 9.89 & 2.86 & 12.84 \\
\hline
\end{tabular}

Table 5. DF20, MPD and statistical values from 3, 5 and 6 test sections

\begin{tabular}{|c|c|c|c|c|c|c|c|c|c|c|c|c|}
\hline Site No. & 3 & & & & 5 & & & & 6 & & & \\
\hline \multirow{2}{*}{$\begin{array}{l}\text { Measuring } \\
\text { point }\end{array}$} & \multicolumn{2}{|l|}{ Left } & \multicolumn{2}{|l|}{ Right } & \multicolumn{2}{|l|}{ Left } & \multicolumn{2}{|l|}{ Right } & \multicolumn{2}{|l|}{ Left } & \multicolumn{2}{|l|}{ Right } \\
\hline & DF20 & MPD & DF20 & MPD & DF20 & MPD & DF20 & MPD & DF20 & MPD & DF20 & MPD \\
\hline 1 & 0.55 & 0.75 & 0.56 & 0.85 & 0.51 & 0.38 & 0,49 & 0.37 & 0.54 & 0.37 & 0.53 & 0.39 \\
\hline 2 & 0.54 & 0.98 & 0.55 & 0.74 & 0.52 & 0.46 & 0.48 & 0.41 & 0.51 & 0.41 & 0.57 & 0.42 \\
\hline 3 & 0.49 & 1.23 & 0.51 & 1.11 & 0.48 & 0.41 & 0.52 & 0.43 & 0.52 & 0.45 & 0.55 & 0.36 \\
\hline 4 & 0.44 & 1.32 & 0.45 & 1.09 & 0.54 & 0.39 & 0.51 & 0.41 & 0.49 & 0.38 & 0.53 & 0.29 \\
\hline 5 & 0.45 & 1.21 & 0.48 & 1.24 & 0.50 & 0.34 & 0.52 & 0.36 & 0.51 & 0.36 & 0.55 & 0.31 \\
\hline Average & 0.49 & 1.10 & 0.51 & 1.01 & 0.51 & 0.40 & 0.50 & 0.40 & 0.51 & 0.39 & 0.55 & 0.35 \\
\hline STD & 0.04 & 0.21 & 0.04 & 0.18 & 0.02 & 0.04 & 0.02 & 0.03 & 0.02 & 0.03 & 0.01 & 0.05 \\
\hline V (\%) & 9.11 & 18.85 & 8.13 & 18.21 & 3.92 & 9,92 & 3.22 & 6.70 & 3.16 & 8.28 & 2.74 & 13.68 \\
\hline
\end{tabular}


Table 6. DF20, MPD and statistical values from junction

\begin{tabular}{|c|c|c|c|c|c|c|c|c|c|c|c|c|}
\hline \multirow{3}{*}{$\begin{array}{l}\text { Measuring } \\
\text { point }\end{array}$} & \multicolumn{4}{|c|}{ Entry 1} & \multicolumn{4}{|c|}{ Entry 2} & \multicolumn{3}{|c|}{ Entry 3} & \\
\hline & Left & & Right & & Left & & Right & & Left & & Right & \\
\hline & DF20 & MPD & DF20 & MPD & DF20 & MPD & DF20 & MPD & DF20 & MPD & DF20 & MPD \\
\hline 1 & 0.58 & 0.38 & 0.59 & 0.32 & 0.61 & 0.29 & 0.58 & 0.32 & 0.63 & 0.29 & 0.61 & 0.34 \\
\hline 2 & 0.56 & 0.36 & 0.53 & 0.34 & 0.59 & 0.31 & 0.57 & 0.38 & 0.56 & 0.32 & 0.57 & 0.28 \\
\hline 3 & 0.53 & 0.41 & 0.49 & 0.45 & 0.57 & 0.37 & 0.55 & 0.34 & 0.57 & 0.35 & 0.56 & 0.42 \\
\hline 4 & 0.49 & 0.42 & 0.46 & 0.39 & 0.59 & 0.28 & 0.57 & 0.41 & 0.53 & 0.41 & 0.56 & 0.38 \\
\hline 5 & 0.51 & 0.34 & 0.50 & 0.31 & 0.61 & 0.32 & 0.58 & 0.36 & 0.52 & 0.31 & 0.53 & 0.28 \\
\hline Average & 0.53 & 0.38 & 0.51 & 0.36 & 0.59 & 0.31 & 0.57 & 0.36 & 0.56 & 0.34 & 0.57 & 0.34 \\
\hline STD & 0.03 & 0.03 & 0.04 & 0.05 & 0.01 & 0.03 & 0.01 & 0.03 & 0.04 & 0.04 & 0.03 & 0.06 \\
\hline V (\%) & 6.11 & 7.84 & 8.58 & 14.34 & 2.52 & 9.99 & 1.92 & 8.63 & 6.88 & 12.43 & 4.55 & 16.22 \\
\hline
\end{tabular}

There were no significant differences between the results of both DF20 and MPD values obtained from the left and right path. Fig 4 show an example of braking curves for different test sections from DFTester. DF20 values from 1 and 2 test section on the SMA pavement do not differ. However the higher values of DF20 were obtained for AC compared to SMA on straight segment sections $1,2,4$. This is caused by the higher content of fine aggregate in AC than SMA.

This confirms the results obtained in laboratory, which showed that SMA and AC with aggregate of the same PSV are characterized by different coefficients of friction [6]. Although there is no difference between average values of DF20 on the test sections 2 and 3 , there are variations of DF20 on the measurement points on the section 3 . At the beginning of deceleration lane on 1, 2 measuring points there are higher values of DF20 compared to measurement points 4 and 5 (Table 5). This is the result of braking maneuver at the end of deceleration lane which affects the intensity of polishing aggregates and changes microtexture.

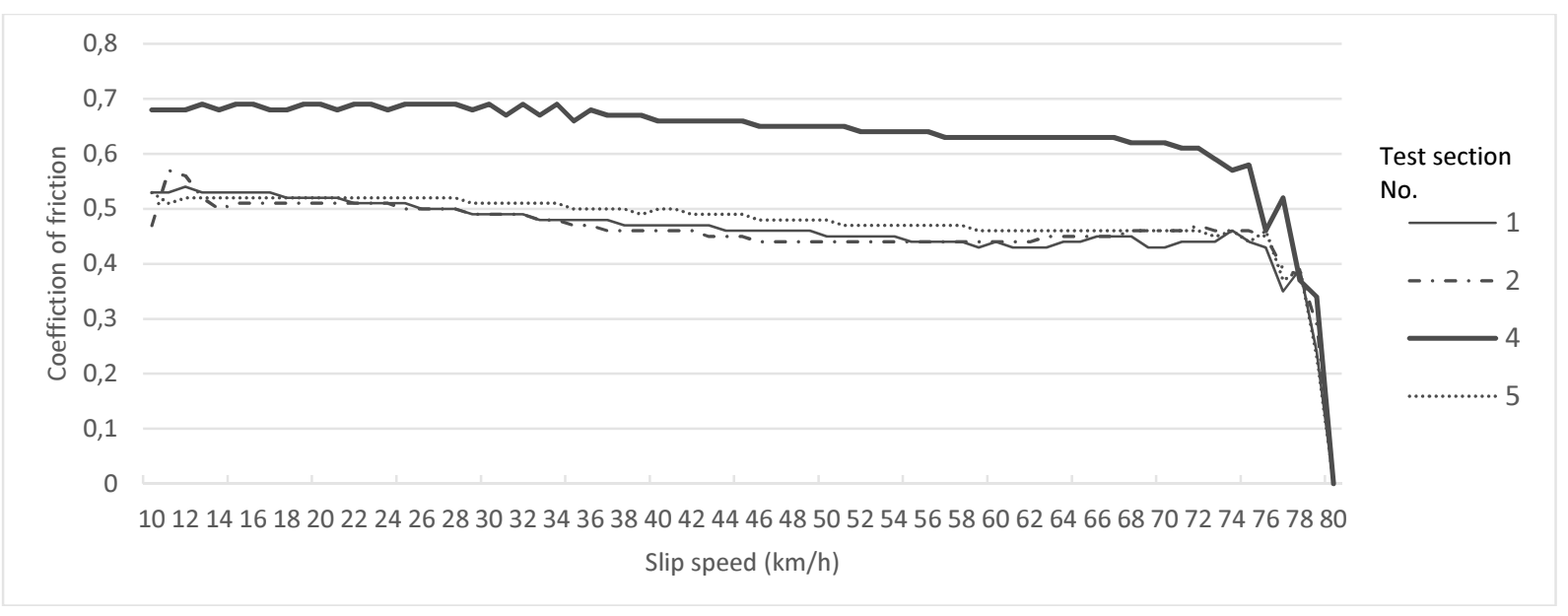

Fig. 4. Example of braking curves from the DFT device

Based on in-situ observations it was noticed that for both types of wearing course (SMA and AC), the binder covering aggregate has not been completely removed despite the pavements were over a year in operation under heavy traffic. It may be caused by the fact that modified binder was used in these both mixture. On the straight segment section AC had a higher value of DF20 than on junction area. Similarly like on the deceleration lane, on the curves and junction area higher intensity of vehicle braking takes place.

SMA is characterized by higher values of MPD than AC. This is caused by the higher content of coarse aggregate in SMA than AC. The highest MPD value was obtained for SMA on 2 and 3 test sections. The lowest MPD was received for asphalt concrete on straight section. 


\section{Assessment of skid resistance using IFI}

Skid resistance was assessed based on IFI (International Friction Index). The IFI uses two parameters: Sp and F60. Sp in kph is initially computed from MPD in mm as follows:

$$
S_{p}=a+b \cdot T x
$$

where: Tx - macrotexture (MPD or MTD) measurement, $(\mathrm{mm}) ; \mathrm{a}, \mathrm{b}$ - calibration constants dependent on the method used for determining Tx; for MPD: $a=14.2$ and $b=89.7$.

F60 was determined from the formula:

$$
F 60=A+B \cdot F R 60
$$

where: A, B - calibration constants dependent upon the measurement equipment; for DFTester A $=0.081, \mathrm{~B}=0.732$;

FR 60 - adjusted value of coefficient of friction measurement $\mathrm{FR}(S)$ at a slip speed of $S$ to a slip speed of $60 \mathrm{kph}$ was determined from the formula:

$$
F R 60=F R S \cdot \exp \left(S-60 / S_{p}\right)
$$

where: FR(S) - coefficient of friction at selected slip speed $S$; for DFTester FRS equals DF20 value at slip speed $S=20 \mathrm{kph}$.

\begin{tabular}{|c|c|c|c|}
\hline Site No. & Path & $\mathrm{Sp}$ & F60 \\
\hline \multirow[t]{2}{*}{1} & Left & 92.51 & 0.32 \\
\hline & Right & 92.24 & 0.32 \\
\hline \multirow[t]{2}{*}{2} & Left & 120.76 & 0.36 \\
\hline & Right & 105.51 & 0.34 \\
\hline \multirow[t]{2}{*}{3} & Left & 112.69 & 0.33 \\
\hline & Right & 104.44 & 0.34 \\
\hline \multirow[t]{2}{*}{4} & Left & 49.63 & 0.29 \\
\hline & Right & 41.47 & 0.25 \\
\hline \multirow[t]{2}{*}{5} & Left & 49.72 & 0.25 \\
\hline & Right & 49.72 & 0.25 \\
\hline \multirow[t]{2}{*}{6} & Left & 49.54 & 0.25 \\
\hline & Right & 45.95 & 0.25 \\
\hline \multirow[t]{2}{*}{7 (Entry 1) } & Left & 48.47 & 0.25 \\
\hline & Right & 46.67 & 0.24 \\
\hline \multirow[t]{2}{*}{7 (Entry 2) } & Left & 42.37 & 0.25 \\
\hline & Right & 46.67 & 0.25 \\
\hline \multirow[t]{2}{*}{7 (Entry 3) } & Left & 44.34 & 0.25 \\
\hline & Right & 44.77 & 0.29 \\
\hline
\end{tabular}

$\mathrm{Sp}$ and F60 values are given in Table 7.

Table 7. Results of IFI (Sp, F60)

There are differences in Sp values obtained on test section 1 and sections 2, 3 on SMA pavement. Despite the fact that mixture properties are alike, the macrotexture is different. F60 values obtained on curves and junction are not satisfy requirements in other countries [1], [7]

Once the IFI is obtained, it is possible to calculate coefficient of friction $\mathrm{F}(S)$ at any slip speed $S$. Coefficient of friction at some other slip speeds $\mathrm{S}$ was calculated from the formula:

$$
F(S)=F 60 \cdot \exp \left[(60-S) / \mathrm{S}_{p}\right] .
$$

The calculation results are presented in Fig. 5 . 


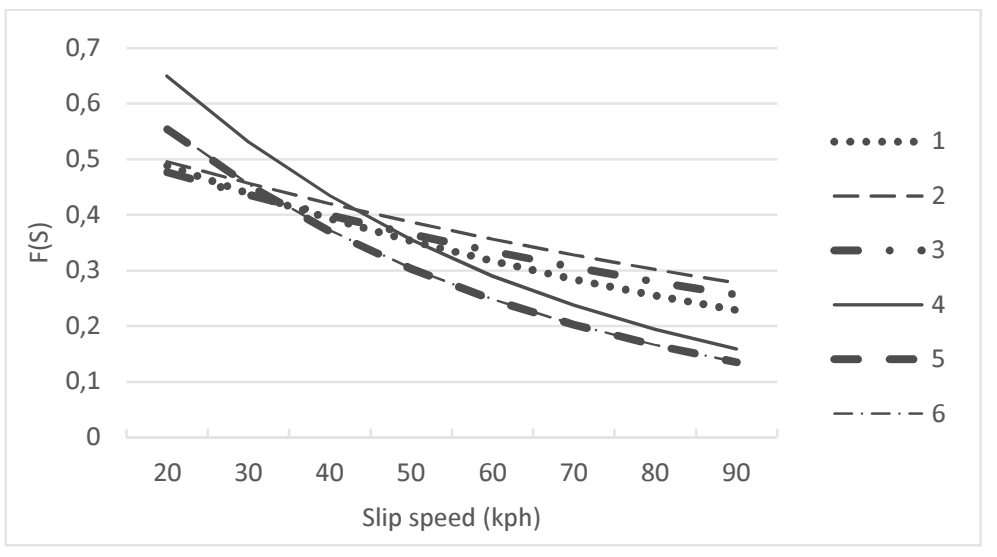

Fig. 5. Coefficient of friction at some other slip speeds $S$ - test sections

It was found out that pavements made of AC had higher coefficient of friction than SMA at low speed, while SMA had higher coefficient of friction than $\mathrm{AC}$ at high speeds. Coefficient of friction has lower values on curves and junction area than on straight road segments on the same type of pavement.

\section{Conclusions}

Skid resistance depends on type of wearing course, its texture and sites location. Most important factors are microtexture and macrotexture. So far measurements using the device SRT-3 do not fully reflect the phenomena occurring in a contact area between tire and pavement under braking. It is important to evaluate skid resistance based on both microtexture and macrotexture. Application of CTMeter and DFTester devices for measurements is a good solution, especially at curves and junction area. It has been proven that the same asphalt mixture could produce different skidding resistance under slightly different site conditions. In addition, IFI can be calculated using the MPD from the CTM measurement and the DF20 at a slip speed of 20 kph from the DFT measurement. As the result of the analysis it was shown at low speed AC had higher coefficient of friction than SMA, while at high speeds SMA had higher coefficient of friction than AC. For road managers it would be valuable to have predictive tools to maintenance and optimize mixtures use for pavements road.

\section{References}

[1] Hall, J. W.; Smith, K. L.; Titus-Glover, L.; Wambold, J. C.; Yager, T. J.; Rado, Z. 2009. Guide for pavement friction. NCHRP. Web-only document 108. Contractor's Final Report NCHRP Project 01-43. Transportation Research Board of the National Academes

[2] Rado, Z. 2009. Evaluating performance of limestone prone to polishing . Final report. The Thomas D. Larson Pennsylvania Transportation Institute.

[3] Roe, P. G.; Hartshorne, S. A. 1998. The Polished Stone Value of aggregates and in-service skidding resistance. TRL Report 322. United Kingdom.

[4] Henry, J. J.; Abe, H.; Kameyama, S.; Tamai, A.; Kasahara, A.; Saito, K. 2000. Determination of the International Friction Index (IFI) using the Circular Texture Meter (CTM) and the Dynamic Friction Tester (DFT), $4^{\text {th }}$ Symposium on Surface characteristics, Nante, France

[5] Wilson, D. J.; Black, P. M. 2009. The skid resistance performance of natural New Zealand aggregates using a dynamic friction tester, Quarterly Journal of Engineering Geology and Hydrogeology 42(1): 62-72. http://dx.doi.org/10.1144/1470-9236/07-072

[6] Gardziejczyk, W.; Wasilewska, M. 2012. Assessment of skid resistance of asphalt mixtures in laboratory conditions, Archive of civil engineering 58(4): 521-534.

[7] Yeaman, J. 2005. Are we afraid of the IFI? International Surface Friction Conference: roads and runways: improving safety through assessment and design, 1-4 May, Christchurch, New Zealand. 